\section{Neurocutaneous Diseases}

John A. Aita. Pp. $\mathbf{x}+85$. Springfield, Illinois: Charles C. Thomas. 1966. \$4.75.

Dr. Aita has already established his reputation as a writer who sees the wider perspectives of neurology with his comprehensive textbook on the neurological manifestations of general disease. In this interesting little book on neurocutaneous diseases, he has provided a series of brief notes on the salient features of a selection of disorders that show both dermatological and neurological manifestations, most of them being rare conditions presumed to be of genetic origin or the result of developmental defect. Although the descriptions of these conditions are deliberately in summary form, the book should prove a valuable work of reference since an extensive bibliography is included and, as Dr. Aita mentions in his introduction, it should also stimulate further study of these intriguing disorders, many of which are at present very imperfectly understood.

\section{Notes on Radiological Emergencies}

George Ansell. Edinburgh and London: E. and S. Livingstone. 1966. 10s.

This is a series of charts printed on card and suitable for hanging in an X-ray Department. Each card contains notes suggesting immediate treatment for acute emergencies in an X-ray Department. They include such catastrophies as cardiac arrest, respiratory arrest, acute reaction to local anaesthesia and urographic media, electric shock, embolism, etc.

The advice given is practical and useful and is provided in a form suitable for rapid reference.

\section{Perspectives in Psychopathology. \\ Readings in Abnormal Psychology}

Edited by James $O$. Palmer and Michael J. GoldsteIN. Pp. xiii +234 illustrated. New York and London: Oxford University Press. 1966. 32s.

This book is concerned with the possible patterns of research into abnormal psychology, analysed and displayed for the benefit of interested students. The three main methods of research are taken to be clinical, actuarial and experimental. It is further suggested that the field of investigation should be divided, according to aetiological considerations, into biological, sociocultural and developmental perspectives. Other perspectives such as the behaviouristic view of psychopathology, the role of therapy as a research tool and the purely descriptive approach are acknowledged but not discussed further.

The six main approaches chosen by the editors are illustrated by the presentation of approximately thirty previously published papers which represent tetween them these various approaches and which comprise the majority of the substance of the book. These papers are, on the whole, well chosen. After the brief preface the editors' role is restricted to a short introduction to each section. This volume does serve the purpose claimed for it by the editors. On the other hand it seems a somewhat ponderous way for their views to be presented, with a collection of papers which cannot be wholly representative but which are sufficiently bulky to extend the book to over 400 pages. However, it may be that there is value for students in the examination of so many well classified, concrete examples and the price of the book is reasonable.
Pulmonary Embolism. Mechanism and Management

Robert Marshall. Pp. xiv + 163. Springfield, Illinois: Charles C. Thomas. 1965. \$7.

Much of our recent knowledge of Pulmonary Embolism has stemmed from the work of the Nuffield Department of Surgery at the Radcliffe Infirmary. In this monograph, Dr. Marshall, from this Department, presents an outstanding review of this entire subject.

Following a brief historical review, Dr. Marshall then considers the causation of thrombosis occurring in the veins of the legs and pelvis, evaluating his numerous publications which incriminate damage to the vessel wall, stagnation of blood and changes in blood coagulability, but finding none wholly satisfactory. He considers in great detail the events following impaction of an embolus and produces convincing evidence in favour of the fatal role of obstruction to the pulmonary circulation, rather than reflex changes in the pulmonary vessels, or bronchoconstriction. A full discussion on the role of drugs in treatment of experimental emboli has very little clinical application.

The clinical features of pulmonary embolus, pulmonary infarction and recurrent pulmonary embolism and cor pulmonale, are very well presented and fully discussed. The role of special diagnostic investigations, including pulmonary function tests and use of radio-isotopes is also well presented.

The prevention and treatment of venous thrombosis is well reviewed, and it is reassuring to learn that proper application of elastic compression achieving a pressure of $15 \mathrm{~mm} \mathrm{Hg}$., is sufficient to reduce the total cross section of leg veins from 2.65 to $0.53 \mathrm{sq}$. $\mathrm{cm}$., and to increase the mean linear velocity of blood flow from 0.5 to 2.5 $\mathrm{cm}$. per second. The treatment of the pulmonary embolism is also fully considered, including embolectomy and the use of Fibrinolysins.

The only criticism of this book lies in the failure of the author to consider the problem posed by the patient, frequently encountered in clinical practice, who presents with pulmonary emboliation, for no apparent reason. Otherwise this is a wholly admirable book, to be thoroughly recommended to all clinicians, and all interested in the problems of intra-vascular thrombosis.

\section{The Stomach}

Stewart Wolf. Pp. 321 illustrated. New York and London: Oxford University Press. 1966. 56s.

There can be few medical students whose introduction to the physiology of the stomach did not begin with the description of the studies by Wolf and Wolff on Tom and his gastric fistula. For almost 17 years Dr. Wolf studied Tom who was an assistant in the physicians laboratory until he, Tom, died of gastric carcinoma and pyelonephritis. The contribution of both these men is undoubted in particular the close relationship between the emotions and gastric function was clearly established in this 'seemingly unimpressive small man.'

This book presents Tom's story and describes work in other humans with a gastric fistula (including Alexis St. Martin). In addition current views on gastric structure and function are reviewed. However, the value of the book lies principally in its description of a study of one patient. We are grateful to Dr. Wolf for summarizing in a convenient form the results of his years of study. 